\title{
Urban park characteristics, genetic variation, and historical demography of white-footed mouse (Peromyscus leucopus) populations in New York City
}

Severe fragmentation is a typical fate of native remnant habitats in cities, and urban wildlife with limited dispersal ability are predicted to lose genetic variation in isolated urban patches. However, little information exists on the characteristics of urban green spaces required to conserve genetic variation. In this study, we examine whether isolation in New York City (NYC) parks results in genetic bottlenecks in white-footed mice (Peromyscus leucopus), and test the hypotheses that park size and time since isolation are associated with genetic variability using nonlinear regression and information-theoretic model selection. White-footed mice have previously been documented to exhibit male-biased dispersal, which may create disparities in genetic variation between males and females in urban parks. We use genotypes of 18 neutral microsatellite data and four different statistical tests to assess this prediction. Given that sex-biased dispersal may create disparities between population genetic patterns inferred from bi- vs. uni-parentally inherited markers, we also sequenced a 324 bp segment of the mitochondrial D-loop for independent inferences of historical demography in urban $P$. leucopus. We report that isolation in urban parks does not necessarily result in genetic bottlenecks; only three out of 14 populations in NYC parks exhibited a signature of a recent bottleneck at 18 neutral microsatellite loci. Mouse populations in larger urban parks, or parks that have been isolated for shorter periods of time, also do not generally contain greater genetic variation than populations in smaller parks. These results suggest that even small networks of green spaces may be sufficient to maintain the evolutionary potential of native species with certain characteristics. We also found that isolation in urban parks results in weak to nonexistent sex-biased dispersal in a species known to exhibit male-biased dispersal in less fragmented environments. In contrast to nuclear loci, mitochondrial D-loop haplotypes exhibited a mutational pattern of demographic expansion after a recent bottleneck or selective sweep. Estimates of the timing of this expansion suggest that it occurred concurrent 
with urbanization of NYC over the last few dozens to hundreds of years. Given the general non-neutrality of mtDNA in many systems and evidence of selection on related coding sequences in urban $P$. leucopus, we argue that the $P$. leucopus mitochondrial genome experienced recent negative selection against haplotypes not favored in isolated urban parks. In general, rapid adaptive evolution driven by urbanization, global climate change, and other human-caused factors is underappreciated by evolutionary biologists, but many more cases will likely be documented in the near future. 
2 Jason Munshi-South

3 Department of Biological Sciences and the Louis Calder Center-Biological Field Station,

4 Fordham University, 53 Whippoorwill Road, Armonk, NY 10504 USA

5 Christopher Nagy

6 Mianus River Gorge Preserve, 167 Mianus River Road, Bedford, NY 10506 USA

7 Corresponding author: Jason Munshi-South

8 Louis Calder Center, Fordham University, 53 Whippoorwill Road, Armonk, NY

9 E-mail: jason@NYCevolution.org

10 Tel: (914) 273-3078 ext 20

11 Fax: (914) 273-6346 


\section{Introduction}

13 Populations in fragmented habitats are predicted to lose genetic variation due to drift and local

14 adaptation through natural selection (Varvio et al. 1986), although this decline may be opposed

15 by gene flow and mutations that add new genetic variants to individual populations (Slatkin

16 1987). If sufficiently severe, fragmentation promotes a cycle of reduced population size,

17 inbreeding, and loss of genetic variation (Ellstrand \& Elam 1993). The relative importance of

18 genetic variation in this 'extinction vortex' has been widely debated (Ashley et al. 2003), but the

19 magnitude of inbreeding depression (Soulé \& Mills 1998) and initial population sizes (Fagan \&

20 Holmes 2006) both influence the probability of population extinction. Hundreds of empirical

21 studies indicate that population genetic structure is magnified in fragmented habitats due to

22 restricted gene flow (Bohonak 1999; Keyghobadi 2007), but many of these studies do not test

23 explicit population genetic hypotheses (Emel \& Storfer 2012). Additionally, the interacting roles

24 of population density, fragment area, habitat quality, and spatial configuration in driving loss of

25 genetic variation vary widely across taxa or ecosystems (Gibbs 2001; Fahrig 2003).

26 Severe fragmentation is a typical fate of native remnant habitats in cities (Shochat et al.

27 2006), and urban wildlife with limited dispersal ability are predicted to exhibit genetic

28 differentiation between urban habitat patches (often city parks or similar semi-natural green

29 infrastructure). A growing body of "urban conservation genetics" (Noël \& Lapointe 2010)

30 literature has documented genetic structure between populations of multiple city-dwelling taxa,

31 including mammals (Wandeler et al. 2003; Munshi-South \& Kharchenko 2010; Chiappero et al.

32 2011), amphibians (Hitchings \& Beebee 1997; Noel et al. 2007; Munshi-South et al. 2013),

33 reptiles (Delaney et al. 2010), birds (Bjorklund et al. 2010; Vangestel et al. 2011; Unfried et al.

34 2013), and insects (Watts et al. 2004; Jha \& Kremen 2013). These studies reported either stable

35 or reduced genetic variability in urban vs. non-urban habitats, but few examined associations

36 between patch attributes and population genetic indicators. Larger urban parks harbor 
37 increasingly greater numbers of species (Goddard et al. 2010; Strohbach et al. 2013), and may

38 also protect individual populations against genetic bottlenecks, inbreeding, and loss of genetic

39 variation. Understanding the relationship between park size and genetic variation will aid efforts

40 to manage networks of small urban patches (Millard 2008; Vergnes et al. 2012).

41 In this study, we examine whether isolation in New York City (NYC) parks results in

42 genetic bottlenecks in white-footed mice (Peromyscus leucopus). We then use nonlinear

43 regression and information-theoretic model selection to test the hypotheses that park size and

44 time since isolation are associated with genetic variability. Our previous research on this system

45 found substantial genetic structure among urban white-footed mice, and indicators of genetic

46 variation at neutral microsatellites were moderately high but not uniform across parks (Munshi-

47 South \& Kharchenko 2010). In contrast, P. leucopus in fragmented woodlots surrounded by

48 agricultural matrix exhibit only weak genetic structure and high genetic variability (Mossman \&

49 Waser 2001). Emigration rates from small patches may be higher than from large patches in

50 these P. leucopus metapopulations (Anderson \& Meikle 2010), presumably because the smallest

51 patches contain the highest population densities (Krohne \& Hoch 1999). Our previous estimates

52 of both recent and historical migration between parks were very low between most pairs of parks

53 in NYC (Munshi-South 2012). Thus, the probability of bottlenecks and levels of genetic

54 variation in urban white-footed mice should be influenced more by park size and how long the

55 sites have been isolated than by migration rates. The short time frame of urbanization in NYC

56 also indicates that mutations will be a weak contributor to contemporary genetic diversity.

$57 \quad$ Natal dispersal in most mammals (Greenwood 1980; Dobson 1982), including $P$.

58 leucopus (Wolff et al. 1988), is male-biased. This pattern may result in lower average relatedness

59 and weaker genetic structure between members of the dispersing vs. philopatric sex (Mossman \&

60 Waser 1999; Munshi-South 2008). In urban populations, we predict that a male bias in dispersal

61 will be weak to nonexistent due to an inability for either sex to successfully disperse out of 
62 isolated urban patches. We use neutral microsatellite data and four different statistical tests to

63 assess this prediction. Given that sex-biased dispersal may create disparities between population

64 genetic patterns inferred from bi- vs. uni-parentally inherited markers, we also sequenced a 324

65 bp segment of the mitochondrial D-loop. We use these sequence data for independent inferences

66 of population demography and genetic variation of urban P. leucopus. Specifically, we used

67 mismatch distribution analyses to statistically assess the evidence for a population expansion

68 after a bottleneck or selective sweep in NYC parks, and estimate the number of generations since

69 any such events.

70 Urban biodiversity is increasingly recognized as worthy of conservation attention

71 (Elmqvist et al. 2013), but the population genetics of wildlife in cities has received relatively little

72 attention (Magle et al. 2012). This study is one of the first to examine population bottlenecks,

73 genetic variation, and sex-biased dispersal of wildlife in relation to the characteristics of urban 74 parks.

\section{Methods}

\section{Sampling and microsatellite data collection}

77 To examine associations between urban park size and genetic variation, we trapped and sampled

78 genetic material from 294 white-footed mice from 14 urban parks in NYC from 2008-2009.

79 These study sites encompass nearly all of the large forested areas known to harbor P. leucopus in

80 the NYC boroughs of the Bronx, Manhattan, and Queens. Brooklyn and Staten Island were

81 excluded from the study a priori due to logistical constraints. The trapping sites within each park

82 were usually located in "Forever Wild" nature preserves that are protected to maintain urban

83 biodiversity and ecosystem services. These "Forever Wild" sites are situated within a broader

84 park matrix of mowed lawns, playgrounds, athletic fields and other managed landscapes. Most

85 trapping sites consisted of an invasive understory and an Appalachian oak-hickory or 
successional northern hardwoods canopy as defined by Edinger et al. (2002), with successional shrublands, oldfields, and salt marsh edges at three Queens sites (Fort Tilden, Willow Lake, and Jamaica Bay, respectively; Table 1).

Mice were trapped over 2-3 nights at each site using Sherman Live Traps (9"x9"x3") baited with birdseed. For genetic analysis, we snipped the terminal $1 \mathrm{~cm}$ or less of each mouse's tail before releasing them alive at the site of capture. Tail snips were stored in $80-95 \%$ ethanol until DNA extraction. Next, we genotyped all mice at 18 unlinked microsatellite loci, and calculated for each population across all loci the mean number of alleles, effective number of alleles (i.e. the estimated number of equally frequent alleles in an ideal population), number of private alleles, and observed heterozygosity in GenAlex 6.2 (Peakall \& Smouse 2006). All animal handling procedures were approved by the CUNY Brooklyn College Institutional Animal Care and Use Committee (Protocol No. 229). Permission to collect genetic samples from wild white-footed mice was granted by the New York State Department of Environmental Conservation (License to Collect or Possess Wildlife Nos. 1262 and 1603), Gateway National Recreation Area, the NYC Department of Parks and Recreation, and the Central Park

Conservancy. Full descriptions of study sites, microsatellite loci, genotyping protocol, and calculation of basic population genetic statistics are available in Munshi-South \& Kharchenko (2010). The microsatellite genotypes are also available on the Dryad Digital Repository (doi: 10.5061/dryad.1893).

Analysis of historical demography and sex-biased dispersal using microsatellite loci

We tested for genetic bottlenecks in each park using the program BOTTLENECK 1.2 (Piry et al. 1999 ) and the authors' recommended settings for microsatellites (two-phase mutations; 95\% single-step and 5\% multi-step mutations). We report results of a one-tailed Wilcoxon's signed 
109

110

111

112

113

114

115

116

117

118

119

120

121

122

123

124

125

126

127

128

129

130

131

rank test based on 10,000 randomizations to examine the hypothesis of significant heterozygosity excess in bottlenecked populations (Cornuet \& Luikart 1996).

To test for sex-biased dispersal between NYC parks in urban white-footed mice, we used the "biased dispersal" module in FSTAT 2.9.3 (Goudet et al. 2002) to compare multiple indices between males and females: the mean and variance of a corrected assignment index $\left(A I_{c}\right)$, average relatedness, and $F_{\mathrm{ST}}$ calculated separately for males and females. The assignment index calculates the probability that an individual's genotype occurred by chance in a population, and thus individuals of the dispersing sex should exhibit lower mean $A I_{c}$ values (Paetkau et al. 1995; Favre et al. 1997). We used one-sided $P$ values calculated using 10,000 randomizations of the data to test the predictions of lower mean $A I_{c}$, greater variance in $A I_{c}$, lower average relatedness, and lower $F_{\mathrm{ST}}$ for males than for females. These indices were calculated for the entire dataset, as well as for two subsets of populations: Bronx and Queens. Previous work indicated that migration rates are nonzero between at least some populations in each subset (Munshi - South 2012), but results were not different from the total dataset.

\section{Modeling of park size vs. genetic diversity}

We modeled five basic measures of genetic variation against area and time since isolation of each of the 14 NYC parks to examine the effect of park attributes on genetic diversity. Genetic measures included the mean number of alleles $\left(\mathrm{N}_{\mathrm{A}}\right)$, effective number of alleles $\left(\mathrm{N}_{\mathrm{E}}\right)$, number of private alleles $\left(\mathrm{N}_{\mathrm{P}}\right)$, and observed heterozygosity $\left(\mathrm{H}_{\mathrm{O}}\right)$ reported in Munshi-South \& Kharchenko (2010) , as well as $\Theta\left(4 N_{E} \mu\right.$ where $\mu=$ mutation rate) estimated using MIGRATE- $n$ (Beerli 2006) and reported in Munshi-South (2012). These genetic measures were modeled with three geographic covariates: total park area (TA), natural habitat area defined as secondary or primary forest cover (HA), and the proportion of habitat area out of the total area (PH). Geographic

132 layers of park boundaries were obtained from the New York City Department of Parks and 
133 Recreation. Habitat delineations were digitized by hand in ArcGIS 10.1 using aerial photographs

134 and our own knowledge of each parks' layout.

135 We also modeled genetic variability with the number of years since each park became

136 isolated to examine the hypothesis that longer periods of isolation result in lower genetic

137 variability. We used two different proxies for time since isolation: 1) the years since each park

138 was officially founded, and 2) years since major infrastructure projects (primarily multi-lane

139 parkways and expressways) were erected around park perimeters. Our rationale for the former

140 date was that many parks in NYC were likely the last large green spaces in the general area at the

141 time of their establishment, and thus their founding dates should reflect the order in which they

142 became isolated. We used a time since isolation based on infrastructure projects because many

143 NYC parks are at least partially circled by major roadways that likely present major obstacles to

144 wildlife. Networks of parkways were constructed during the Robert Moses era of park

145 management in NYC (Caro 1974), and these parkways may have been the most important factor

146 in loss of connectivity between populations. Information that would facilitate more precise

147 inference of the time since isolation is generally not available. Aerial photos of NYC from 1924

148 and 1951 (available at http://maps.nyc.gov/doitt/nycitymap/) indicate that most parks were

149 surrounded by urban development by 1924, and thus isolated concurrent with or before their

150 founding. Many maps exist from throughout NYC's history, but unfortunately these maps

151 generally do not contain information on the quality or extent of vegetation (Benson 2013).

152 Generating habitat cover through more complex predictive approaches for even one snapshot of

153 time in NYC is a monumental effort outside the scope of this study (Sanderson 2009).

154 Genetic (dependent) variables were examined with eighteen candidate models, each of

155 which consisted of various combinations of the three geographic covariates and time since

156 founding (F): an intercept-only model, the four univariate models (TA, HA, PH, and F), the eight

157 combinations of two covariates, the four combinations of three covariates, and a global model 
158 with all four covariates $(\mathrm{TA}+\mathrm{HA}+\mathrm{PH}+\mathrm{F})$. Intercept-only models were included in the

159 candidate model sets of each genetic variable to serve as a baseline for detecting a covariate

160 effect: if a model performed substantially better than the intercept-only model, we interpreted this

161 result as evidence for an effect of that model's covariates upon the respective diversity index. We

162 calculated maximum likelihood estimates of model parameters for each model, and then models

163 were ranked using Akaike's Information Criterion $\left(\mathrm{AIC}_{\mathrm{c}}\right)$ corrected for finite sample sizes

164 (Burnham \& Anderson 2002). In brief, this approach compares a set of models, each

165 representing an a priori hypothesis, to determine which model is closer to a hypothetical model

166 that encompasses all of reality, i.e., one that perfectly models the dependent variable in all

167 instances. The advantages and general differences of an information-theoretic approach versus

168 traditional hypothesis testing were discussed by Anderson et al. (2000).

169 Each of the six genetic diversity indices was modeled with regression techniques

170 appropriate to the distribution of that index, based on the overall sample frequency distribution,

171 e.g., right-skewed variables used gamma regression. If we were unsure of the proper regression

172 method between a choice of two, the method that minimized the deviance of the global model

173 was used. Traditionally, a transformation (e.g., log, square-root) is applied to non-normal data to

174 facilitate the use of regression; however, this approach may be inferior to using regression

175 techniques that directly match the distributions of the variables in question (Gea-Izquierdo \&

176 Cañellas 2009). All modeling was performed in R 2.15 (Team 2012). Gamma and GLM

177 regression were specifically performed using the MASS package (Venables \& Ripley 2002), and

178 analyses with a Tweedie distribution using the "tweedie" package (Dunn \& Dunn 2013).

\section{Mitochondrial DNA sequencing and analyses}

180 We sequenced a $324 \mathrm{bp}$ region of the mitochondrial D-loop for a subset of 110 individuals from

181 above to examine historical demography and genetic variation using a maternally inherited 
182 marker. We designed D-loop PCR primers from a consensus sequence created using all $P$.

183 leucopus D-loop sequences available on GenBank in September 2009 (accession numbers

184 available from authors upon request). We created the consensus sequence from a ClustalW

185 alignment conducted in BioEdit 7 (Hall 1999), and chose the primers using the Primer3 web

186 interface (Rozen \& Skaletsky 1999). We conducted PCR in $25 \mu$ volumes using Illustra

187 PuReTaq Ready-to-Go PCR beads (G.E. Life Sciences, Piscataway, NJ) with one $\mu$ l forward

188 primer (Pleucopus_DloopFor 5'-ACCATCCTCCGTGAAATCAG-3'), one $\mu 1$ reverse primer

189 (Pleucopus_DloopRev 5'-AAAAAGCATATGAGGGGAGTG-3'), and one $\mu$ l of template DNA

190 with concentrations of $25-50 \mathrm{ng} / \mu \mathrm{l}$. We performed PCR on a thermocycler for 30 cycles of

$19195^{\circ} \mathrm{C}$ for $30 \mathrm{sec}, 55^{\circ} \mathrm{C}$ for $30 \mathrm{sec}$, and $72^{\circ} \mathrm{C}$ for $1 \mathrm{~min}$, and then cleaned PCR products using

192 Qiaquick PCR purification kits (Qiagen, Valencia, CA). We then sequenced both forward and

193 reverse strands using the standard GenomeLab DTCS quick start protocol on a Beckman Coulter

194 CEQ 8000 sequencer (Beckman Coulter, Brea, CA). Finally, we edited and aligned the

195 sequences using Sequencer 4.8 (Gene Codes, Ann Arbor, MI) and BioEdit 7. All unique,

196 unaligned D-loop haplotypes have been deposited on GenBank (Accession: KF986735-

197 KF986771), and a Nexus haplotype file used for the analyses below is available on the Figshare

198 digital repository (doi: 10.6084/m9.figshare.881830).

199 We calculated summary statistics for all D-loop sequences and subsets from Bronx,

200 Manhattan, and Queens using DnaSP 5.1 (Rozas et al. 2003). Statistics we used to describe D-

201 loop variation included the number of polymorphic sites, nucleotide diversity, number of

202 haplotypes, haplotype diversity, and the average number of nucleotide differences. To examine

203 deviations from neutrality and population size changes, we also calculated Tajima's $D$ and Fu's

$204 F s$, and assessed their significance using 10,000 coalescent simulations. We also calculated

205 mismatch distributions (i.e. the observed pairwise nucleotide site differences) under a model of

206 population expansion to examine demographic changes, and assessed significance of the 
207 observed distributions using 10,000 coalescent simulations of the raggedness statistic, $r$ (Rogers

208 \& Harpending 1992), and the R2 statistic (Ramos-Onsins \& Rozas 2002).

\section{Results \& Discussion}

210 Analysis of historical demography and sex-biased dispersal using nuclear loci

211 Tests for genetic bottlenecks did not detect significant heterozygosity excess in most NYC parks

212 (Table 1), indicating that bottlenecks have not been a general phenomenon in these populations.

213 Three populations tested positive for recent bottlenecks, but there was no general trend towards

214 bottlenecks in large or small parks (Table 1). The estimated habitat area (HA) was among the

215 lowest of the 14 parks for two of the populations exhibiting bottlenecks (Central Park and Willow

216 Lake), but other small habitat patches were not positive for bottlenecks. These results suggest

217 that very small urban forest fragments (e.g. $<50$ ha) may support sufficiently large populations of

218 native small mammals to prevent severe genetic drift from population crashes. The relatively

219 high population densities of $P$. leucopus that have been recorded in small patches may explain

220 this resiliency (Krohne \& Hoch 1999). However, the lack of evidence for bottlenecks is still

221 surprising given that substantial genetic drift has occurred in these populations over the past

222 century (Munshi-South \& Kharchenko 2010), and drift efficiently reduces allelic diversity in

223 isolated populations (Allendorf 1986). This type of analysis should be interpreted cautiously

224 because the results may be influenced by deviations from the underlying assumptions about

225 microsatellite mutation rates. Many of our microsatellite markers were first identified in the

226 closely-related P. maniculatus, and thus in P. leucopus may not strictly adhere to a stepwise

227 mutation model with a low frequency of multi-step mutations. These microsatellites generally

228 adhered to other expectations (e.g. Hardy-Weinberg equilibrium) and performed well in a number

229 of other analyses, and thus we feel it is unlikely that we are failing to detect true bottlenecks in 
230 these populations. Changes to the assumed frequencies of single- vs. multi-step mutations in our

231 Bottleneck runs did not significantly alter the results.

232 We also found little evidence of sex-biased dispersal in urban white-footed mice, either

233 across all NYC populations or clustered sites in Bronx or Queens (Table 2). Only one of four

234 statistics varied in the predicted direction for male-biased dispersal (mean $\mathrm{AI}_{\mathrm{c}}$ ), but this sex

235 difference was not robustly supported. Males in our sample had less likely genotypes than

236 females given the overall genetic characteristics of our sample, as has been argued previously to

237 support male-biased dispersal in this species (Mossman \& Waser 1999). Our previous findings of

238 very low migration rates between urban populations (Munshi-South 2012) coupled with these

239 dispersal results suggest that neither males nor females migrate between urban patches at

240 anywhere near the high rates reported for less severe fragmentation scenarios (Anderson \&

241 Meikle 2010). However, males may still disperse more often or farther away from their natal

242 sites within patches than females disperse. Our study design and sample sizes for each site did

243 not allow us to test within-patch dispersal patterns.

244 Few studies have examined bottlenecks or sex-biased dispersal in species isolated in

245 urban forest fragments. Our results for white-footed mice suggest that other small vertebrates

246 with limited dispersal ability (especially non-volant species) can avoid genetic bottlenecks if they

247 maintain high population densities in small urban parks. Common forest dwellers in eastern

248 North America that are known to thrive in urban parks include red-backed salamanders,

249 Plethodon cinereus (Noël \& Lapointe 2010), and northern short-tailed shrews, Blarina

250 brevicauda (Brack Jr 2006). The former species responds similarly to urban forest fragmentation

251 as $P$. leucopus in terms of rapid genetic differentiation between fragments but little apparent loss

252 of genetic diversity (Gibbs 1998; Noel et al. 2007). We predict that B. brevicauda will exhibit

253 similar patterns. In contrast, the northern dusky salamander, Desmognathus fuscus, loses genetic

254 variation in isolated urban stream / seepage habitats (Munshi-South et al. 2013), but this pattern 
255

256

257

258

259

260

261

262

263

264

265

266

267

268

269

270

271

272

273

274

275

276

277

278

may not hold for species such as the northern two-lined salamander, Eurycea bislineata, that maintain higher population densities and occupy a greater diversity of streams in urbanized watersheds (Pehek 2007).

\section{Modeling of park characteristics vs. genetic diversity}

The values for $\mathrm{N}_{\mathrm{A}}, \mathrm{N}_{\mathrm{E}}$, and $\mathrm{N}_{\mathrm{P}}$ were right skewed continuous and thus were modeled using gamma regression (Gea-Izquierdo \& Cañellas 2009), while $\mathrm{H}_{\mathrm{O}}$ was best modeled with a standard generalized linear model (GLM). $\Theta$ was highly right-skewed and thus was best modeled using a Tweedie distribution with an inverse Gaussian dispersion parameter (i.e., $p=3$ ). The inverse Gaussian parameterization of the generalized Tweedie distribution is useful in modeling variables that are right-skewed and continuous (Jorgensen 1987; Dunn \& Smyth 2001). In all model sets the global model deviance / degrees of freedom were less than or equal to 1.0, indicating adequate model fit (i.e. no overdispersion). For all diversity measures except $\Theta$ the interceptonly models had the most parsimonious fit (Table 3), indicating no discernible pattern between the geographic covariates / time since park founding and the genetic diversity measures (Figure 1). $\Theta$ increased as the percent of habitat area in each park increased (Table 3; Figure 1). The model analyzing $\Theta$ with percent habitat and time since founding was also highly ranked, but due to the effect of percent habitat rather than time since founding. Two geographic covariate pairs total area (TA) and habitat area (HA), and HA and percent habitat $(\mathrm{PH})$ - were correlated $(r=$ 0.68 and 0.63 , respectively); however, models with these combinations were universally poor. While there was considerable variation in measures of allelic diversity among NYC parks, there was no clear relationship between park size / time since founding and genetic variation. Neither estimate of the time since founding was successful at explaining genetic variation, and we only report the results from the time since founding (Table 3, Figure 1). Observed heterozygosity did not differ very much between most populations. This latter result suggests 
279 that even the smallest and most isolated habitat patches maintain population densities that are

280 adequate to preserve heterozygosity. Additionally, the parks we sampled in NYC may all fall

281 below a size threshold beyond which white-footed mice maintain high population densities and

282 genetic variation, sometimes referred to as a "synurbic" threshold (Francis \& Chadwick 2012).

283 Larger urban parks support higher population densities of gray squirrels (Sciurus carolinensis),

284 although the relative proportions of tree and building cover also influence these densities (Parker

$285 \&$ Nilon 2012). Most of the parks analyzed in this study contained similar types of mouse

286 habitat: an invasive vegetative understory with an oak-hickory or successional northern

287 hardwoods canopy (Munshi-South \& Kharchenko 2010). However, it is possible that

288 unmeasured ecological variability between NYC parks, such as differences in habitat quality,

289 food availability, or predator abundance (Levi et al. 2012), would better explain genetic variation

290 than park size or the time since founding. Genetic variation in P. leucopus may alternatively

291 respond to ecological variables in non-generalizable ways. For example, competition between

292 squirrels, chipmunks (Tamias striatus), and white-footed mice in northeastern forest fragments is

293 weak to nonexistent, except in certain sites with idiosyncratic characteristics (Brunner et al.

294 2013).

295 NYC parks with the largest habitat areas may be instructive about the influence of highly

296 site-specific characteristics on genetic diversity. Jamaica Bay (JB) had one of the largest habitat

297 areas but the lowest measures of genetic diversity (Figure 3). This site differs from the others in

298 that the habitat is composed of salt marsh and sandy scrub in addition to forests, and thus may be

299 lower-quality habitat than the typical urban forest. We ran the modeling procedure without

300 Jamaica Bay, but the overall results did not change. In contrast to Jamaica Bay, Van Cortlandt

301 (VC) is one of the largest parks in NYC and also exhibited the highest allelic diversity. Besides

302 large size, Van Cortland contains a diversity of forest and meadow habitats, and roads may

303 promote weak genetic differentiation between mice in the park (Munshi-South \& Kharchenko 
304 2010). The remaining parks may have not sufficiently differed in size and genetic diversity to

305 identify a general trend, although the Van Cortland results suggest that very large urban parks

306 may harbor the greatest genetic variation if they are diverse in vegetation and structure.

307 Park isolation time was generally not successful at explaining genetic variation. Similar

308 to park size, there may not be enough variation in the time since isolation of NYC parks to

309 observe a general trend in genetic variation. Alternatively, our use of the years since a park was

310 founded or the years since construction of major infrastructre as proxies for how long parks have

311 been ecologically isolated may not have been accurate. Given that much of NYC was heavily

312 urbanized concurrent with the founding of these parks (particularly outside Manhattan), we feel

313 that our choices were justified. However, future historical reconstructions of the NYC landscape

314 (Sanderson 2009) may fruitfully revisit this question. For the specific question of ecological and

315 genetic isolation of wildlife, some parks may also have a complicated history of human

316 transformation that will be difficult to account for in studies such as ours. For example, both

317 Central Park in Manhattan and Flushing Meadows-Willow Lake in Queens are largely human-

318 made habitats constructed after periods of heavy human disturbance (farms and villages in

319 Central Park, and a massive ash dump in Flushing Meadows). Thus, it is not clear whether

320 white-footed mouse populations have always been present at these sites, or recolonized after

321 some period of absence. Relatively high levels of genetic variation suggest the former scenario,

322 but definitive historical trapping records are not available.

323 Mitochondrial DNA, demographic changes, and selection

324 We identified 37 haplotypes among 324 bp mitochondrial D-loop sequences obtained for 110

325 individuals (Table 4). Haplotype diversity was very high, but the average number of nucleotide

326 differences between haplotypes was low to moderate. Analysis of haplotypes by landmass

327 (Bronx, Manhattan \& Queens) revealed similar patterns, although Queens exhibited lower 
328 diversity and average number of differences than the other two landmasses or the total sample,

329 despite a larger number of haplotypes and polymorphic sites (Table 4).

330 Significant Tajima's $D$ and Fu's $F s$ values for the total NYC sample and Queens indicate

331 that urban P. leucopus underwent a recent population expansion after a bottleneck or selective

332 sweep. Alternatively, the D-loop may have experienced genetic hitchhiking (i.e. genetic draft)

333 due to negative selection on linked mitochondrial genes. The observed mismatch distributions

334 for NYC and Queens closely fit the expected unimodal distribution for a recent population

335 expansion (Figure 2). This fit was statistically supported by the raggedness and R2 statistics

336 (Table 4). Statistics indicating a demographic expansion were generally not significant for the

337 Bronx and Manhattan subsamples, but this discrepancy may be due to a much smaller sample

338 size for these areas of the city. Environmental or demographic stochasticity can exert

339 considerable influence on mismatch distributions, and such an effect would be enhanced for

340 small sample sizes.

341 We estimated the time (in generations) since the bottleneck or selective sweep reflected in

342 the mismatch distributions (Figure 2$)$ using the $\tau$ parameter $(2 \mu \mathrm{t}$; Table 4$)$ and four pedigree-

343 derived estimates of the mitochondrial D-loop mutation rate $\left(3.52 \times 10^{-5}, 1.92 \times 10^{-5}, 1.28 \times 10^{-5}\right.$,

344 and $4.19 \times 10^{-6} /$ site / generation) in humans (Santos et al. 2005). To our knowledge, no similar

345 D-loop mutation rate estimates have been published for rodents. The four human mutation rates

346 were multiplied by $324 \mathrm{bp}$, and then used to calculate $\mathrm{t}=\tau / 2 \mu$ for Queens $(38.5,70.6,105.9$, and

347323.9 generations, respectively) and the entire NYC sample $(91.5,167.8,251.7$, and 769.8

348 generations). These results suggest that demographic expansion after a bottleneck or selective

349 sweep was concurrent with urbanization of NYC (i.e. in the last few hundred years), assuming a

350 conservative generation time in urban P. leucopus between 0.5-1.0 years. The expansion also

351 occurred more recently in Queens than NYC overall, potentially because Queens was not heavily

352 urbanized until after the construction of bridges, tunnels, and commuter rail connecting Queens to 
353 Manhattan in the early twentieth century. However, these estimated times should be interpreted

354 cautiously given that we used D-loop mutation rates estimated from human pedigrees. These

355 human estimates were calculated over sequences that were a few hundred bp longer than those

356 analyzed in this study. If mutation rates are heterogeneous along the D-loop, then these human

357 estimates may over- or under-estimate the mutation rate for P. leucopus. Additionally,

358 mitochondrial mutation rates vary widely across mammals with variation in body size,

359 temperature, metabolic rates (Gillooly et al. 2005), age at female sexual maturity, and lifespan

360 (Nabholz, Glémin, et al. 2008). All of these factors predict that P. leucopus will have a higher

361 mitochondrial mutation rate than humans, and thus our reported times since a bottleneck or

362 selective sweep are likely all underestimated. If mutation rates are substantially higher in $P$.

363 leuсориs, then the timing estimates could indicate that the demographic event or sweep occurred

364 considerably more recently than urbanization / isolation of NYC Parks.

365 In the absence of independent evidence, it is difficult to distinguish between bottlenecks

366 and selection as explanations for the mismatch distributions observed in this study. Only a few

367 NYC populations exhibited evidence of recent bottlenecks at nuclear microsatellite loci, thus

368 undermining the bottleneck argument for the mtDNA data. Alternatively, the mtDNA results may

369 reflect a bottleneck that occurred further back in time than could be detected by the microsatellite

370 data, or the mtDNA reflects a bottleneck specific to this matrilineal marker. These alternatives

371 are unlikely given that the D-loop is also a hypervariable marker appropriate for detecting recent

372 demographic events, and the events creating the mismatch distribution were estimated to occur in

373 the last few dozens to hundreds of generations. A matrilineal bottleneck signature is also unlikely

374 given that males and females did not differ at multiple population genetic parameters estimated

375 using nuclear data (Table 2).

376 The mismatch distributions may be better explained by negative selection against

377 unfavorable mtDNA haplotypes once these populations became isolated in urban habitat patches 
378 with novel selection pressures. In this scenario, the D-loop would have hitchhiked along with the

379 surviving haplotypes containing favored alleles in mtDNA protein-coding regions. The

380 mitochondrial genome is now widely acknowledged to have experienced selective sweeps in

381 many if not most taxa, and thus some authors have called into question its utility in demographic

382 estimation (Bazin et al. 2006; Nabholz, Mauffrey, et al. 2008; Balloux 2010). Theoretical

383 arguments and some empirical results show that factors such as changes in population density

384 (Lankau \& Strauss 2011) and increased temperature (Franks et al. 2013; Schilthuizen \&

385 Kellermann 2013) are likely to produce evolutionary responses in human-altered environments

386 (Sih et al. 2011; Mueller et al. 2013). These factors or others related to metabolism (such as a

387 dietary shift in urban habitats) may have driven mitochondrial selective sweeps in NYC's white-

388 footed mice.

389

Mitochondrial DNA sequencing of contemporary and museum specimens of P. leucopus

390 from the Chicago area indicated that mtDNA haplotypes changed rapidly over a timeframe

391 corresponding to human development of natural areas (Pergams et al. 2003). Mismatch

392 distributions of D-loop haplotypes from these populations (Pergams \& Lacy 2008) closely

393 resemble those presented here for NYC mice, indicating that mitochondrial selection during

394 urbanization may have been a general phenomenon throughout the range of $P$. leucopus. Pergams

$395 \&$ Lacy (2008) argued that these patterns in the Chicago area were due to replacement of the

396 original residents by migrants with a selective advantage; this scenario seems less likely than

397 selection on standing mtDNA variation in NYC because of the high isolation of NYC populations

398 (Munshi-South 2012). The case for selection on mtDNA is further bolstered by our recent

399 finding of several genes exhibiting elevated signatures of selection in urban vs. rural P. leucopus

400 populations in the NYC area (Harris et al. 2013). Two of these candidate nuclear genes encode

401 mitochondrial proteins (39S ribosomal protein L51 and Camello-like protein 1), suggesting that

402 mitonuclear pathways may be active targets of selection in urban populations (Dowling et al. 
403 2008). Full mitochondrial genome sequences and large-scale mRNA-Seq datasets for urban and

404 rural populations of white-footed mice can be used in the future to examine potential mitonuclear

405 associations.

\section{Conclusions}

407 We report here that isolation in urban parks does not necessarily result in genetic bottlenecks or

408 substantial loss of genetic variation in urban wildlife populations. White-footed mouse

409 populations in larger urban parks, or parks that have been isolated for fewer years, do not

410 generally contain greater genetic variation than smaller or older parks, although we could not

411 address site-specific variability between parks that may exert a greater influence on genetic

412 variation than size alone. These results should be encouraging to conservation biologists working

413 in human-dominated landscapes, as even small networks of green spaces may be sufficient to

414 maintain self-sustaining populations and evolutionary potential of some native species (Goddard

415 et al. 2010). We also found that isolation in urban parks results in weak to nonexistent sex-biased

416 dispersal in a species known to exhibit male-biased dispersal in less fragmented environments.

417 The breakdown of this dispersal mechanism likely explains the pervasive genetic differentiation

418 among P. leucopus populations in different NYC parks. In contrast to nuclear loci, mitochondrial

419 D-loop haplotypes exhibited a mutational pattern of demographic expansion after a recent

420 bottleneck or selective sweep. Estimates of the timing of this expansion indicate that it occurred

421 concurrent with urbanization of NYC over the last few dozens to hundreds of years. Given the

422 general non-neutrality of mtDNA in many systems and evidence of selection on coding sequences

423 in urban P. leucopus, we argue that the P. leucopus mitochondrial genome experienced recent

424 negative selection against haplotypes not favored in isolated urban parks. In general, rapid

425 adaptive evolution driven by urbanization, global climate change, and other human-caused 
426 factors is underappreciated by evolutionary biologists, but many more cases will likely be

427 documented in the near future.

\section{Acknowledgments}

429 We thank Anna Bernstein and Stephen E. Harris for assistance with the mitochondrial

430 sequencing. William Amos, Seth Magle, Charles Nilon, and two anonymous reviewers provided

431 many constructive comments that greatly improved our manuscript. The New York State

432 Department of Environmental Conservation, the NYC Department of Parks \& Recreation,

433 Central Park Conservancy, and New York Botanical Garden graciously provided permission to

434 sample white-footed mice in urban parks.

\section{References}

436 Allendorf FW. 1986. Genetic drift and the loss of alleles versus heterozygosity. Zoo Biology

$437 \quad 5: 181-190$.

438 Anderson DR, Burnham KP, Thompson WL. 2000. Null Hypothesis Testing: Problems,

439 Prevalence, and an Alternative. The Journal of Wildlife Management 64:912-923.

440 Anderson CS, Meikle DB. 2010. Genetic estimates of immigration and emigration rates in

441 relation to population density and forest patch area in Peromyscus leucopus.

$442 \quad$ Conservation Genetics 11:1593-1605.

443 Ashley MV, Willson MF, Pergams ORW, O’Dowd DJ, Gende SM, Brown JS. 2003.

444 Evolutionarily enlightened management. Biological Conservation 111:115-123.

445 Balloux F. 2010. The worm in the fruit of the mitochondrial DNA tree. Heredity 104:419-420. 
446 Bazin E, Glémin S, Galtier N. 2006. Population Size Does Not Influence Mitochondrial Genetic Diversity in Animals. Science 312:570-572.

448 Beerli P. 2006. Comparison of Bayesian and maximum likelihood inference of population genetic 449 parameters. Bioinformatics 22:341-345.

450 Benson E. 2013. The Urbanization of the Eastern Gray Squirrel in the United States. Journal of 451 American History 100:691-710.

452

453

454

455

456

457

458
Bjorklund M, Ruiz I, Senar J. 2010. Genetic differentiation in the urban habitat: the great tits (Parus major) of the parks of Barcelona city. Biological Journal of the Linnean Society 99:9-19.

Bohonak AJ. 1999. Dispersal, gene flow, and population structure. The Quarterly Review of Biology 74:21-45.

Brack Jr V. 2006. Short-tailed Shrews (Blarina brevicauda) exhibit unusual behavior in an urban environment. Urban Habitats 4:127-132.

Brunner JL, Duerr S, Keesing F, Killilea M, Vuong H, Ostfeld RS. 2013. An Experimental Test of Competition among Mice, Chipmunks, and Squirrels in Deciduous Forest Fragments. PLOS ONE 8:e66798.

Burnham KP, Anderson DR. 2002. Model selection and multi-model inference: a practical information-theoretic approach. Springer.

Caro RA. 1974. The Power Broker: Robert Moses and the Fall of New York. Alfred a Knopf, New York, NY. 
466 Chiappero MB, Panzetta-Dutari GM, Gómez D, Castillo E, Polop JJ, Gardenal CN. 2011.

467 Contrasting genetic structure of urban and rural populations of the wild rodent Calomys

468 musculinus (Cricetidae, Sigmodontinae). Mammalian Biology - Zeitschrift für

469 Säugetierkunde 76:41-50.

470 Cornuet JM, Luikart G. 1996. Description and Power Analysis of Two Tests for Detecting Recent $471 \quad$ Population Bottlenecks From Allele Frequency Data. Genetics 144:2001 -2014.

472 Delaney KS, Riley SPD, Fisher RN. 2010. A Rapid, Strong, and Convergent Genetic Response to 473 Urban Habitat Fragmentation in Four Divergent and Widespread Vertebrates. PLoS ONE $474 \quad 5: \mathrm{e} 12767$.

475 Dobson SF. 1982. Competition for mates and predominant juvenile male dispersal in mammals. 476 Animal behaviour 30:1183-1192.

477 Dowling DK, Friberg U, Lindell J. 2008. Evolutionary implications of non-neutral mitochondrial 478 genetic variation. Trends in Ecology \& Evolution 23:546-554.

479 Dunn PK, Dunn MPK. 2013. Package "tweedie."

480 Dunn PK, Smyth GK. 2001. Tweedie family densities: methods of evaluation. Proceedings of the 481 16th International Workshop on Statistical Modelling, Odense, Denmark pp. 2-6.

482 Edinger GJ, Evans DJ, Gebauer S, Howard TG, Hunt DM, Olivero AM. 2002. Ecological 483 Communities of New York State. New York Natural Heritage Program, New York State 484 Department of Environmental Conservation, Albany, NY. 
485 Ellstrand NC, Elam DR. 1993. Population Genetic Consequences of Small Population Size:

486

487 Implications for Plant Conservation. Annual Review of Ecology and Systematics 24:217-

488

489

490

491

492

493

494

495

496

497

498

499

500

501

502

503

504 242.

Elmqvist T, Fragkias M, Goodness J, Guneralp B, Marcotullio PJ, McDonald RI, Parnell S, Schewenius M, Sendstad M, Seto KC, Wilkinson C. 2013. Urbanization, Biodiversity and Ecosystem Services: Challenges and Opportunities. Springer Open, Dordrecht, Germany.

Emel S, Storfer A. 2012. A decade of amphibian population genetic studies: synthesis and recommendations. Conservation Genetics 13:1685-1689.

Fagan WF, Holmes EE. 2006. Quantifying the extinction vortex. Ecology Letters 9:51-60.

Fahrig L. 2003. Effects of habitat fragmentation on biodiversity. Annual Review of Ecology, Evolution, and Systematics 34:487-515.

Favre L, Balloux F, Goudet J, Perrin N. 1997. Female-biased dispersal in the monogamous mammal Crocidura russula: evidence from field data and microsatellite patterns. Proceedings of the Royal Society of London. Series B: Biological Sciences 264:127-132.

Francis RA, Chadwick MA. 2012. What makes a species synurbic? Applied Geography 32:514521.

Franks SJ, Weber JJ, Aitken SN. 2013. Evolutionary and plastic responses to climate change in terrestrial plant populations. Evolutionary Applications in press.

Gea-Izquierdo G, Cañellas I. 2009. Analysis of Holm Oak Intraspecific Competition Using Gamma Regression. Forest Science 55:310-322. 
505 Gibbs JP. 1998. Genetic structure of redback salamander Plethodon cinereus populations in 506 continuous and fragmented forests. Biological Conservation 86:77-81.

507 Gibbs JP. 2001. Demography versus habitat fragmentation as determinants of genetic variation in $508 \quad$ wild populations. Biological Conservation 100:15-20.

509 Gillooly JF, Allen AP, West GB, Brown JH. 2005. The rate of DNA evolution: Effects of body 510 size and temperature on the molecular clock. Proceedings of the National Academy of $511 \quad$ Sciences of the United States of America 102:140-145.

512 Goddard MA, Dougill AJ, Benton TG. 2010. Scaling up from gardens: biodiversity conservation 513 in urban environments. Trends in Ecology \& Evolution 25:90-98.

514 Goudet J, Perrin N, Waser P. 2002. Tests for sex-biased dispersal using bi-parentally inherited 515 genetic markers. Molecular Ecology 11:1103-1114.

Greenwood PJ. 1980. Mating systems, philopatry and dispersal in birds and mammals. Animal behaviour 28:1140-1162.

Hall TA. 1999. BioEdit: a user-friendly biological sequence alignment editor and analysis program for Windows 95/98/NT. Nucleic Acids Symposium Series 41:95-98.

520 Harris SE, Munshi-South J, Obergfell C, O’Neill R. 2013. Signatures of Rapid Evolution in 521 Urban and Rural Transcriptomes of White-Footed Mice (Peromyscus leucopus) in the New York Metropolitan Area. PLoS ONE 8:e74938.

523 Hitchings SP, Beebee TJ. 1997. Genetic substructuring as a result of barriers to gene flow in 524 urban Rana temporaria (common frog) populations: implications for biodiversity $525 \quad$ conservation. Heredity 79:117-127. 
526 Jha S, Kremen C. 2013. Urban land use limits regional bumble bee gene flow. Molecular

$527 \quad$ Ecology 22:2483-2495.

528 Jorgensen B. 1987. Exponential dispersion models. Journal of the Royal Statistical Society.

$529 \quad$ Series B (Methodological) 49:127-162.

530 Keyghobadi N. 2007. The genetic implications of habitat fragmentation for animals. Canadian $531 \quad$ Journal of Zoology 85:1049-1064.

532 Krohne D, Hoch G. 1999. Demography of Peromyscus leucopus populations on habitat patches:

533 the role of dispersal. Canadian Journal of Zoology 77:1247-1253.

534 Lankau RA, Strauss SY. 2011. Newly rare or newly common: evolutionary feedbacks through

535 changes in population density and relative species abundance, and their management

536 implications. Evolutionary Applications 4:338-353.

537 Levi T, Kilpatrick AM, Mangel M, Wilmers CC. 2012. Deer, predators, and the emergence of

$538 \quad$ Lyme disease. Proceedings of the National Academy of Sciences 109:10942-10947.

539 Magle SB, Hunt VM, Vernon M, Crooks KR. 2012. Urban wildlife research: Past, present, and

$540 \quad$ future. Biological Conservation 155:23-32.

541 Millard A. 2008. Semi-natural vegetation and its relationship to designated urban green space at 542 the landscape scale in Leeds, UK. Landscape Ecology 23:1231-1241.

543 Mossman CA, Waser PM. 1999. Genetic detection of sex-biased dispersal. Molecular Ecology 544 8:1063-1067. 
545 Mossman CA, Waser PM. 2001. Effects of habitat fragmentation on population genetic structure 546 in the white-footed mouse (Peromyscus leucopus). Canadian Journal of Zoology 79:285$547 \quad 295$.

548 Mueller JC, Partecke J, Hatchwell BJ, Gaston KJ, Evans KL. 2013. Candidate gene

549 polymorphisms for behavioural adaptations during urbanization in blackbirds. Molecular $550 \quad$ Ecology 22:3629-3637.

551 Munshi-South J. 2008. Female-biased dispersal and gene flow in a behaviorally monogamous 552 mammal, the large treeshrew (Tupaia tana). PLOS One 3:e3228.

553 Munshi-South J, Kharchenko K. 2010. Rapid, pervasive genetic differentiation of urban white554 footed mouse (Peromyscus leucopus) populations in New York City. Molecular Ecology $555 \quad 19: 4242-4254$.

556 Munshi-South J, Zak Y, Pehek E. 2013. Conservation genetics of extremely isolated urban 557 populations of the northern dusky salamander (Desmognathus fuscus) in New York City. $558 \quad$ PeerJ 1:e64.

559 Munshi-South J. 2012. Urban landscape genetics: canopy cover predicts gene flow between 560 white-footed mouse (Peromyscus leucopus) populations in New York City. Molecular $561 \quad$ Ecology 21:1360-1378.

562 Nabholz B, Glémin S, Galtier N. 2008. Strong Variations of Mitochondrial Mutation Rate across 563 Mammals - the Longevity Hypothesis. Molecular Biology and Evolution 25:120-130.

564 Nabholz B, Mauffrey J-F, Bazin E, Galtier N, Glemin S. 2008. Determination of Mitochondrial $565 \quad$ Genetic Diversity in Mammals. Genetics 178:351-361. 
566 Noël S, Lapointe F-J. 2010. Urban conservation genetics: Study of a terrestrial salamander in the 567 city. Biological Conservation 143:2823-2831.

568 Noel S, Ouellet M, Galois P, Lapointe F-J. 2007. Impact of urban fragmentation on the genetic 569 structure of the eastern red-backed salamander. Conservation Genetics 8:599-606.

570 Paetkau D, Calvert W, Stirling I, Strobeck C. 1995. Microsatellite analysis of population structure 571 in Canadian polar bears. Molecular Ecology 4:347-354.

572 Parker TS, Nilon CH. 2012. Urban landscape characteristics correlated with the synurbization of $573 \quad$ wildlife. Landscape and Urban Planning 106:316-325.

574 Peakall ROD, Smouse PE. 2006. GENALEX 6: genetic analysis in Excel. Population genetic 575 software for teaching and research. Molecular Ecology Notes 6:288-295.

576 Pehek E. 2007. Salamander Diversity and Distribution in New York City, 1820 to the Present. Natural History of New York City's Parks and Great Gull Island: Transactions of the

$578 \quad$ Linnaean Society of New York 10:157-182.

579 Pergams ORW, Barnes WM, Nyberg D. 2003. Rapid change in mouse mitochondrial DNA.

$580 \quad$ Nature 423:397.

581 Pergams ORW, Lacy RC. 2008. Rapid morphological and genetic change in Chicago-area 582 Peromyscus. Molecular Ecology 17:450-463.

583 Piry S, Luikart G, Cornuet J-M. 1999. BOTTLENECK: A Computer Program for Detecting 584 Recent Reductions in the Effective Size Using Allele Frequency Data. Journal of 585 Heredity 90:502-503. 
586 Ramos-Onsins SE, Rozas J. 2002. Statistical Properties of New Neutrality Tests Against

587 Population Growth. Molecular Biology and Evolution 19:2092-2100.

588 Rogers AR, Harpending H. 1992. Population growth makes waves in the distribution of pairwise 589 genetic differences. Molecular Biology and Evolution 9:552-569.

590 Rozas J, Sanchez-DelBarrio JC, Messeguer X, Rozas R. 2003. DnaSP, DNA polymorphism

$591 \quad$ analyses by the coalescent and other methods. Bioinformatics 19:2496-2497.

592 Rozen S, Skaletsky H. 1999. Primer3 on the WWW for general users and for biologist

593 programmers. Bioinformatics methods and protocols pp. 365-386. Springer.

594 Sanderson EW. 2009. Mannahatta: A Natural History of New York City. Abrams, New York, NY.

595 Santos C, Montiel R, Sierra B, Bettencourt C, Fernandez E, Alvarez L, Lima M, Abade A, Aluja

596 MP. 2005. Understanding Differences Between Phylogenetic and Pedigree-Derived mtDNA Mutation Rate: A Model Using Families from the Azores Islands (Portugal).

$598 \quad$ Molecular Biology and Evolution 22:1490-1505.

599 Schilthuizen M, Kellermann V. 2013. Contemporary climate change and terrestrial invertebrates:

600 evolutionary versus plastic changes. Evolutionary Applications in press.

601 Shochat E, Warren PS, Faeth SH, McIntyre NE, Hope D. 2006. From patterns to emerging

602 processes in mechanistic urban ecology. Trends in Ecology and Evolution 21:186-191.

603 Sih A, Ferrari MC., Harris DJ. 2011. Evolution and behavioural responses to human-induced 604 rapid environmental change. Evolutionary Applications 4:367-387.

605 Slatkin M. 1987. Gene flow and the geographic structure of natural populations. Science $606 \quad 236: 787-792$. 
607 Soulé ME, Mills LS. 1998. No need to isolate genetics. Science 282:1658-1659.

608 Strohbach MW, Lerman SB, Warren PS. 2013. Are small greening areas enhancing bird 609 diversity? Insights from community-driven greening projects in Boston. Landscape and $610 \quad$ Urban Planning 114:69-79.

611 Team RC. 2012. R: a language and environment for statistical computing. Vienna, Austria: R 612 Foundation for Statistical Computing; 2012. Open access available at: http://cran. r$613 \quad$ project. org.

614 Unfried TM, Hauser L, Marzluff JM. 2013. Effects of urbanization on Song Sparrow (Melospiza 615 melodia) population connectivity. Conservation Genetics 14:41-53.

616 Vangestel C, Mergeay J, Dawson DA, Vandomme V, Lens L. 2011. Spatial heterogeneity in 617 genetic relatedness among house sparrows along an urban-rural gradient as revealed by 618 individual-based analysis. Molecular Ecology 20:4643-4653.

619 Varvio SL, Chakraborty R, Nei M. 1986. Genetic variation in subdivided populations and 620 conservation genetics. Heredity 57:189-198.

621 Venables WN, Ripley BD. 2002. Modern applied statistics with S. Springer, New York, NY.

622 Vergnes A, Viol IL, Clergeau P. 2012. Green corridors in urban landscapes affect the arthropod 623 communities of domestic gardens. Biological Conservation 145:171-178.

624 Wandeler P, Funk SM, Largiader CR, Gloor S, Breitenmoser U. 2003. The city-fox phenomenon: 625 genetic consequences of a recent colonization of urban habitat. Molecular Ecology

$626 \quad 12: 647-656$. 
627 Watts PC, Rouquette JR, Saccheri IJ, Kemp SJ, Thompson DJ. 2004. Molecular and ecological 628 evidence for small-scale isolation by distance in an endangered damselfly, Coenagrion 629 mercuriale. Molecular Ecology 13:2931-2945.

630 Wolff JO, Lundy KI, Baccus R. 1988. Dispersal, inbreeding avoidance and reproductive success 631 in white-footed mice. Animal Behaviour 36:456-465. 


\section{Table 1 (on next page)}

Characteristics of study sites and results of bottleneck tests.

Total area of site, area of potential white-footed mouse habitat, percent habitat, and years since park founding (a proxy for isolation time) for 14 NYC parks analyzed in this study. Site abbreviations follow Figure 1. Final column represents the $P$-value calculated from 10,000 randomizations of the bottleneck test. Significant values appear in bold. 
Table 1. Total area of site, area of potential white-footed mouse habitat, percent habitat, and years since park founding (a proxy for isolation time) for 14 NYC parks analyzed in this study. Site abbreviations follow Figure 1. Final column represents the $P$-value calculated from 10,000 randomizations of the bottleneck test. Significant values appear in bold.

\begin{tabular}{|c|c|c|c|c|c|c|}
\hline$\frac{\infty}{D}$ & Borough & Total area (ha) & $\begin{array}{c}\text { Habitat area } \\
\text { (ha) }\end{array}$ & $\begin{array}{l}\text { Percent } \\
\text { Habitat }\end{array}$ & $\begin{array}{l}\text { Years since } \\
\text { founding }\end{array}$ & $\begin{array}{c}\text { Bottleneck } \\
P \text {-value }\end{array}$ \\
\hline Hunters Island (HI) $\sum$ & Bronx & 247.23 & 103.47 & 0.42 & 121 & 0.71 \\
\hline NY Botanical Garden (NYBG) & Bronx & 98.23 & 37.44 & 0.38 & 114 & 0.838 \\
\hline S. Pelham Bay (SPel) & Bronx & 126.24 & 64.06 & 0.51 & 121 & 0.567 \\
\hline Van Cortlandt Park (VC) $\frac{\Phi}{>}$ & Bronx & 433.15 & 226.83 & 0.52 & 121 & 0.29 \\
\hline Central Park (CP) & Manhattan & 344.05 & 45.23 & 0.13 & 136 & 0.011 \\
\hline Inwood Hill Park (In) & Manhattan & 79.21 & 52.53 & 0.66 & 93 & 0.935 \\
\hline Alley Pond Park (AP) & Queens & 219.66 & 164.26 & 0.75 & 82 & 0.033 \\
\hline Cunningham Park $(\mathrm{CH})$ & Queens & 188.31 & 123.50 & 0.66 & 71 & 0.517 \\
\hline Willow Lake (FM) & Queens & 42.09 & 25.84 & 0.61 & 75 & 0.009 \\
\hline Forest Park (FP) & Queens & 230.68 & 129.84 & 0.56 & 114 & 0.433 \\
\hline Fort Tilden (FT) & Queens & 248.96 & 66.71 & 0.27 & 92 & 0.416 \\
\hline Jamaica Bay (JB) & Queens & 263.38 & 263.38 & 1.00 & 71 & 0.071 \\
\hline Kissena Park (KP) & Queens & 61.44 & 17.68 & 0.29 & 103 & 0.959 \\
\hline Ridgewood Reservoir (RWR) & Queens & 50.58 & 28.40 & 0.56 & 103 & 0.695 \\
\hline
\end{tabular}




\section{Table 2 (on next page)}

Tests for male-biased dispersal in urban white-footed mice.

Results of sex-biased dispersal analysis for white-footed mice across all 14 NYC parks, a subset of six parks in Bronx, and a subset of parks in Queens. 
Table 2. Results of sex-biased dispersal analysis for white-footed mice across all 14 NYC parks, a subset of six parks in Bronx, and a subset of parks in Queens.

\begin{tabular}{cccccc}
\hline & $N$ & mean $\mathrm{AI}_{\mathrm{c}}$ & variance $\mathrm{AI}_{\mathrm{c}}$ & Relatedness & $F_{\mathrm{ST}}$ \\
\hline All NYC Parks & 301 & -- & -- & 0.14 & 0.08 \\
Females & 165 & 0.43 & 31.8 & 0.15 & 0.09 \\
Males & 136 & -0.52 & 32.2 & 0.14 & 0.08 \\
\hline Bronx & 104 & -- & -- & 0.16 & 0.09 \\
Females & 52 & 0.47 & 35.7 & 0.15 & 0.09 \\
Males & 52 & -0.47 & 36.8 & 0.15 & 0.08 \\
\hline Queens & 157 & -- & -- & 0.14 & 0.08 \\
Females & 90 & 0.40 & 31.8 & 0.15 & 0.09 \\
Males & 67 & -0.53 & 26.3 & 0.13 & 0.08 \\
\hline
\end{tabular}




\section{Table 3 (on next page)}

Model selection for park characteristics vs. genetic diversity.

Results of model selection for park characteristics (TA: total area of park; HA: undeveloped habitat area of park; $\mathrm{PH}$ : proportion of park habitat area to total park area; F: years since founding of park) vs. genetic diversity indices. 
Table 3. Results of model selection for park characteristics (TA: total area of park; HA:

undeveloped habitat area of park; $\mathrm{PH}$ : proportion of park habitat area to total park area; F: years since founding of park) vs. genetic diversity indices.

\begin{tabular}{|c|c|c|c|c|c|c|c|}
\hline \multicolumn{4}{|c|}{ Number of alleles $\left(\mathrm{N}_{\mathrm{A}}\right)$} & \multicolumn{4}{|c|}{ Effective number of alleles $\left(\mathrm{N}_{\mathrm{E}}\right)$} \\
\hline Model & LogLike & $\mathrm{k}$ & $\Delta \mathrm{AIC}_{\mathrm{c}}$ & Model & LogLike & $\mathrm{k}$ & $\Delta \mathrm{AIC}_{\mathrm{c}}$ \\
\hline Intercept & -25.91 & 2 & 0.00 & Intercept & -15.20 & 2 & 0.00 \\
\hline TA & -25.54 & 3 & 2.58 & $\mathrm{~F}$ & -15.13 & 3 & 3.17 \\
\hline HA & -25.61 & 3 & 2.71 & HA & -15.15 & 3 & 3.21 \\
\hline $\mathrm{PH}$ & -25.85 & 3 & 3.19 & $\mathrm{HA} * \mathrm{~F}$ & -10.60 & 5 & 3.21 \\
\hline $\mathrm{F}$ & -25.87 & 3 & 3.22 & TA & -15.15 & 3 & 3.22 \\
\hline $\mathrm{HA} * \mathrm{~F}$ & -22.49 & 5 & 5.56 & $\mathrm{PH}$ & -15.19 & 3 & 3.29 \\
\hline $\mathrm{TA}+\mathrm{F}$ & -25.35 & 4 & 6.23 & $\mathrm{PH}+\mathrm{F}$ & -14.98 & 4 & 6.91 \\
\hline $\mathrm{TA}+\mathrm{PH}$ & -25.45 & 4 & 6.43 & $\mathrm{HA}+\mathrm{F}$ & -15.04 & 4 & 7.03 \\
\hline $\mathrm{TA}+\mathrm{HA}$ & -25.51 & 4 & 6.55 & $\mathrm{TA}+\mathrm{F}$ & -15.11 & 4 & 7.18 \\
\hline $\mathrm{HA}+\mathrm{PH}$ & -25.60 & 4 & 6.73 & $\mathrm{TA}+\mathrm{HA}$ & -15.14 & 4 & 7.24 \\
\hline $\mathrm{HA}+\mathrm{F}$ & -25.60 & 4 & 6.74 & $\mathrm{HA}+\mathrm{PH}$ & -15.14 & 4 & 7.24 \\
\hline $\mathrm{PH}+\mathrm{F}$ & -25.85 & 4 & 7.23 & $\mathrm{TA}+\mathrm{PH}$ & -15.14 & 4 & 7.25 \\
\hline $\mathrm{TA} * \mathrm{~F}$ & -24.43 & 5 & 9.45 & $\mathrm{TA} * \mathrm{~F}$ & -13.60 & 5 & 9.22 \\
\hline $\mathrm{TA}+\mathrm{HA}$ & & & & $\mathrm{HA}+\mathrm{PH}$ & & & \\
\hline$+\mathrm{F}$ & -25.33 & 5 & 11.25 & $+\mathrm{F}$ & -14.97 & 5 & 11.96 \\
\hline $\mathrm{TA}+\mathrm{PH}$ & & & & $\mathrm{TA}+\mathrm{PH}$ & & & \\
\hline$+\mathrm{F}$ & -25.35 & 5 & 11.28 & $+\mathrm{F}$ & -14.97 & 5 & 11.96 \\
\hline $\mathrm{TA}+\mathrm{HA}$ & & & & $\mathrm{TA}+\mathrm{HA}$ & & & \\
\hline$+\mathrm{PH}$ & -25.36 & 5 & 11.31 & $+\mathrm{F}$ & -14.99 & 5 & 11.99 \\
\hline $\mathrm{HA}+\mathrm{PH}$ & & & & $\mathrm{TA}+\mathrm{HA}$ & & & \\
\hline$+\mathrm{F}$ & -25.53 & 5 & 11.65 & $+\mathrm{PH}$ & -15.14 & 5 & 12.30 \\
\hline Global & -25.26 & 6 & 17.60 & Global & -14.97 & 6 & 18.46 \\
\hline \multicolumn{4}{|c|}{ Number of private alleles $\left(\mathrm{N}_{\mathrm{P}}\right)$} & \multicolumn{4}{|c|}{ Observed heterozygosity $\left(\mathrm{H}_{\mathrm{o}}\right)$} \\
\hline Model & LogLik & $\mathrm{k}$ & $\Delta \mathrm{AIC}_{\mathrm{c}}$ & Model & LogLik & $\mathrm{k}$ & $\Delta \mathrm{AIC}_{\mathrm{c}}$ \\
\hline Intercept & -33.40 & 2 & 0.00 & Intercept & 25.75 & 2 & 0.00 \\
\hline HA & -33.29 & 3 & 3.07 & PH & 26.13 & 3 & 2.56 \\
\hline $\mathrm{PH}$ & -33.31 & 3 & 3.12 & $\mathrm{~F}$ & 26.11 & 3 & 2.60 \\
\hline TA & -33.40 & 3 & 3.31 & HA & 26.03 & 3 & 2.75 \\
\hline $\mathrm{F}$ & -33.40 & 3 & 3.31 & TA & 25.75 & 3 & 3.31 \\
\hline $\mathrm{TA}+\mathrm{HA}$ & -33.21 & 4 & 6.98 & $\mathrm{TA}+\mathrm{HA}$ & 26.49 & 4 & 5.87 \\
\hline $\mathrm{PH}+\mathrm{F}$ & -33.22 & 4 & 6.99 & $\mathrm{HA}+\mathrm{F}$ & 26.38 & 4 & 6.10 \\
\hline $\mathrm{HA}+\mathrm{PH}$ & -33.27 & 4 & 7.09 & $\mathrm{HA}+\mathrm{PH}$ & 26.20 & 4 & 6.45 \\
\hline $\mathrm{HA}+\mathrm{F}$ & -33.28 & 4 & 7.11 & $\mathrm{PH}+\mathrm{F}$ & 26.20 & 4 & 6.46 \\
\hline $\mathrm{TA}+\mathrm{PH}$ & -33.30 & 4 & 7.16 & $\mathrm{TA}+\mathrm{F}$ & 26.17 & 4 & 6.52 \\
\hline $\mathrm{TA}+\mathrm{F}$ & -33.40 & 4 & 7.35 & $\mathrm{TA}+\mathrm{PH}$ & 26.13 & 4 & 6.59 \\
\hline $\mathrm{HA} * \mathrm{~F}$ & -32.59 & 5 & 10.78 & $\mathrm{HA} * \mathrm{~F}$ & 27.74 & 5 & 8.44 \\
\hline $\mathrm{TA} * \mathrm{~F}$ & -32.88 & 5 & 11.35 & $\mathrm{TA} * \mathrm{~F}$ & 26.70 & 5 & 10.51 \\
\hline $\mathrm{TA}+\mathrm{HA}$ & -33.07 & 5 & 11.74 & $\mathrm{TA}+\mathrm{HA}$ & 26.65 & 5 & 10.61 \\
\hline
\end{tabular}




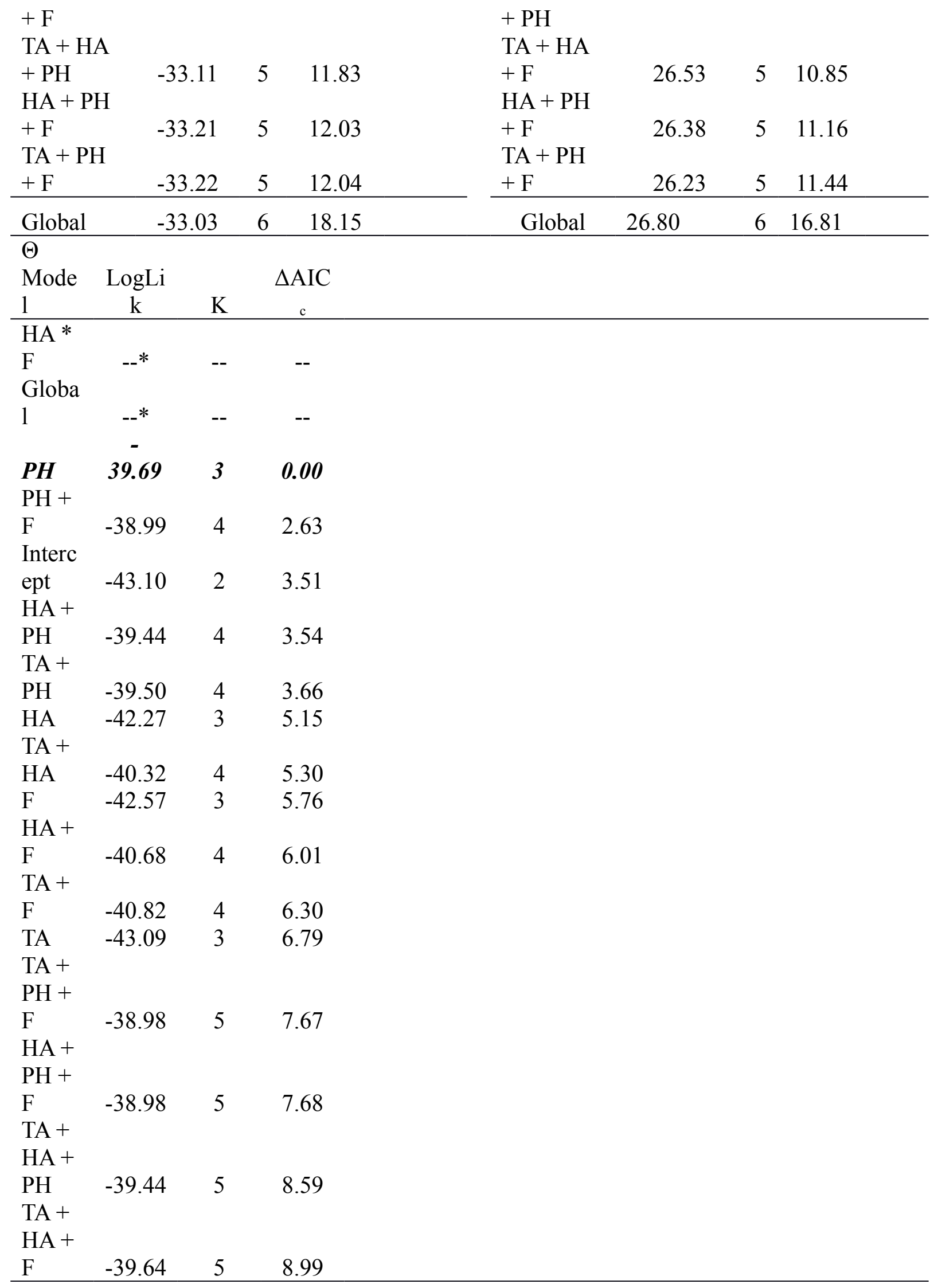


* Denotes model that did not converge

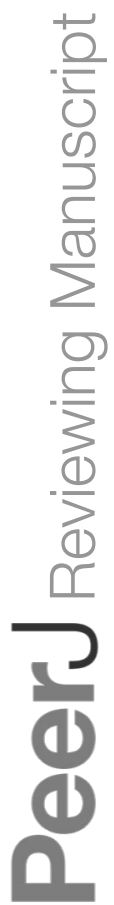




\section{Table 4 (on next page)}

Statistical analysis of $324 \mathrm{bp}$ of the mtDNA D-loop from 110 white-footed mouse individuals.

Significant values are presented in bold text at ${ }^{*} P<0.05$ or ${ }^{* *} P<0.01$ based on 10,000 coalescent simulations in DnaSP.

a Number of individuals haplotyped

b Number of polymorphic sites in D-loop sequence

c Nucleotide diversity

d Number of D-loop haplotypes

e Haplotype diversity

${ }^{f}$ Average number of pairwise nucleotide differences

g Tajima's $D$

h Fu's Fs

' Raggedness statistic for mismatch distribution

j Ramos-Onsins \& Rozas R2 statistic for mismatch distribution

${ }^{k} \tau(2 \mu t)$ calculated for mismatch distribution 
Table 4. Statistical analysis of $324 \mathrm{bp}$ of the mtDNA D-loop from 110 white-footed mouse individuals. Significant values are presented in bold text at $* P<0.05$ or $* * P<$ 0.01 based on 10,000 coalescent simulations in DNASP.

\begin{tabular}{|c|c|c|c|c|c|c|c|c|c|c|c|}
\hline Population & $N^{\mathrm{a}}$ & $P^{\mathrm{b}}$ & $\square^{\mathrm{c}}$ & $H^{\mathrm{d}}$ & $H d^{\mathrm{e}}$ & $K^{\mathrm{f}}$ & $D^{\mathrm{g}}$ & $F s^{\mathrm{h}}$ & $r^{\mathrm{i}}$ & $\mathrm{R} 2^{\mathrm{j}}$ & $\tau^{\mathrm{k}}$ \\
\hline \multirow[t]{2}{*}{ Bronx } & 26 & 1 & 0.008 & 12 & 0.91 & 2.7 & -0.71 & $-4.38 *$ & 0.04 & 0.099 & 2.70 \\
\hline & & 3 & 9 & & & 0 & & & & & \\
\hline \multirow[t]{2}{*}{ Manhattan } & 22 & 1 & 0.0113 & 7 & 0.82 & 3.6 & 1.08 & 0.81 & 0.13 & 0.177 & 2.93 \\
\hline & & 0 & & & & 1 & & & & & \\
\hline \multirow[t]{2}{*}{ Queens } & 56 & 2 & 0.005 & 17 & 0.74 & 1.6 & $-2.1 * *$ & $-11.5 * *$ & $0.029 *$ & $0.041 * *$ & 0.88 \\
\hline & & 2 & 1 & & & 2 & & & & & \\
\hline \multirow[t]{2}{*}{ All } & 110 & 3 & 0.008 & 37 & 0.91 & 2.5 & $-1.73 *$ & $-34.29 * *$ & 0.058 & $0.04 *$ & 2.09 \\
\hline & & 0 & 4 & & & 1 & & & & & \\
\hline
\end{tabular}

${ }^{a}$ Number of individuals haplotyped

${ }^{\mathrm{b}}$ Number of polymorphic sites in D-loop sequence

${ }^{\mathrm{c}}$ Nucleotide diversity

${ }^{\mathrm{d}}$ Number of D-loop haplotypes

${ }^{\text {e }}$ Haplotype diversity

${ }^{\mathrm{f}}$ Average number of pairwise nucleotide differences

g Tajima's $D$

${ }^{\text {h }}$ Fu's $F S$

${ }^{\mathrm{i}}$ Raggedness statistic for mismatch distribution

${ }^{\mathrm{j}}$ Ramos-Onsins \& Rozas R2 statistic for mismatch distribution

${ }^{\mathrm{k}} \tau(2 \mu \mathrm{t})$ calculated for mismatch distribution 


\section{Figure $1_{\text {(on next page) }}$}

Scatterplots of genetic variation vs. characteristics of NYC parks.

Scatterplots of observed heterozygosity (A-D), number of alleles (E-H), number of effective alleles (I-L), number of private alleles (M-P), and $\Theta\left(4 N_{E} \mu ; Q-T\right)$ on the $y$-axis vs. (from left to right) total park area (ha), habitat area (ha), percent habitat, and years since founding on the $x$-axis. Each of 14 NYC parks is labeled within each scatterplot with an abbreviation following Table 1. 

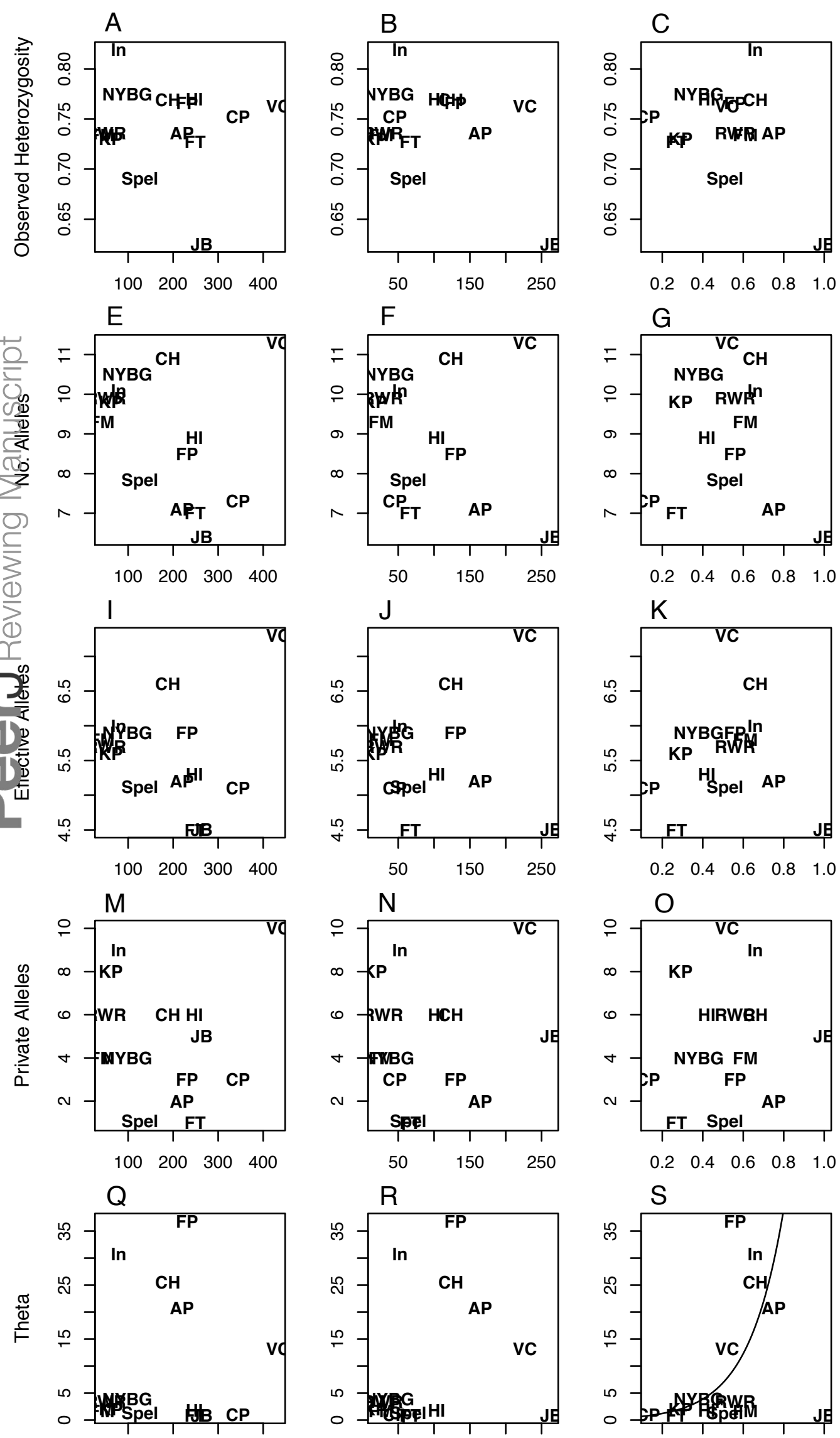

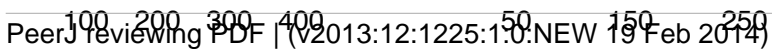
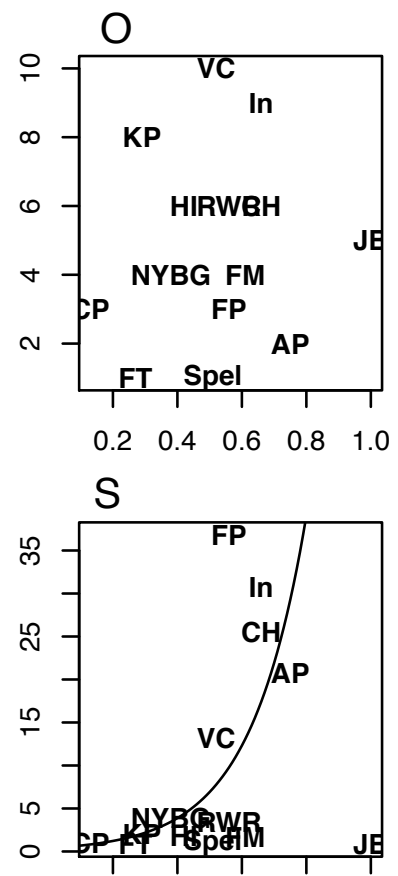

$\begin{array}{lllll}0.2 & 0.4 & 0.6 & 0.8 & 1.0\end{array}$
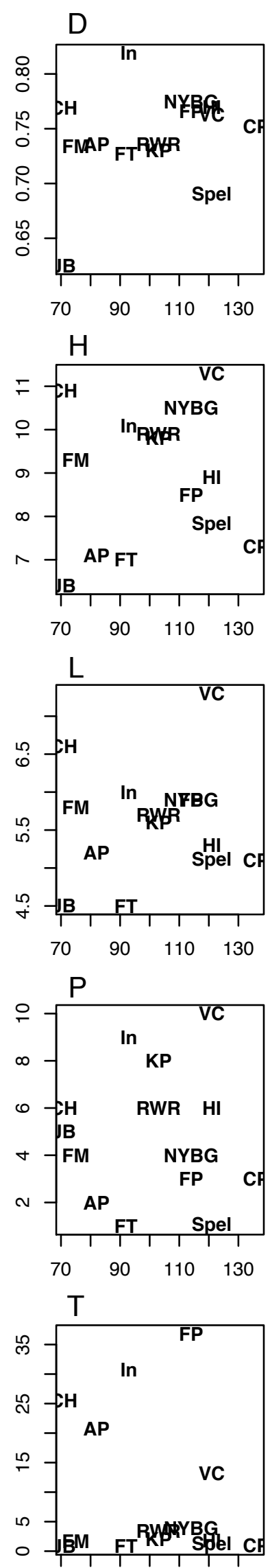

Percent Habitat 


\section{Figure 2}

Mitochondrial mismatch distribution analyses for white-footed mice in NYC that show the influence of a recent population expansion after a bottleneck of selective sweep

Mismatch distributions for $324 \mathrm{bp}$ segment of the mtDNA D-loop for Queens ( $N=56$; top graph) and all NYC samples ( $N=110$; bottom graph). The solid line indicates the observed distribution, and the dotted line indicates the expected distribution for a demographic expansion. 

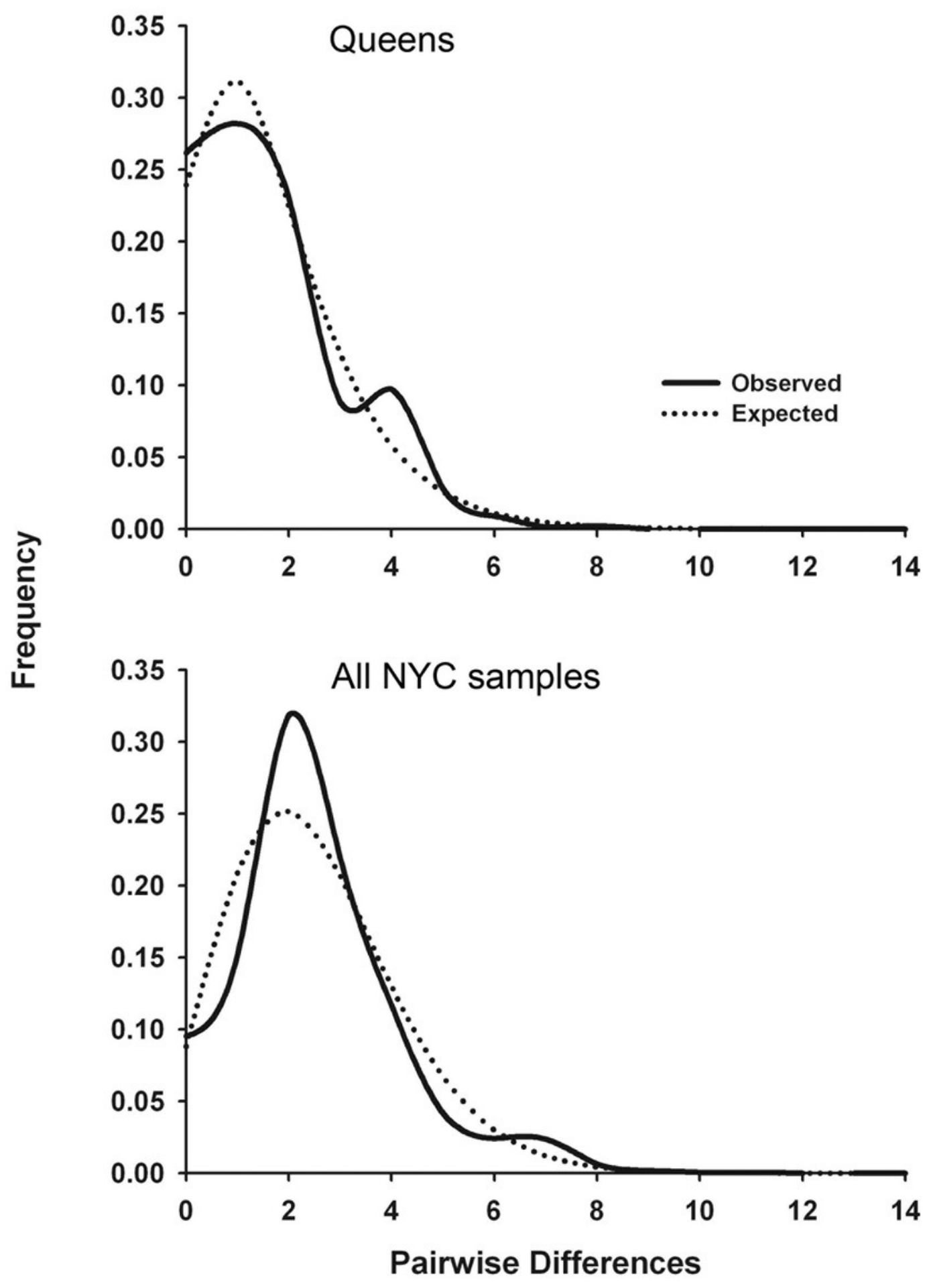